\title{
GAS-LIQUID MASS TRANSFER IN THREE-PHASE FLUIDIZED BEDS
}

\author{
Susumu FUKUSHIMA \\ Department of Chemical Engineering, Kansai University, Suita 564
}

\section{Introduction}

A three-phase fluidized bed (TPFB) is formed when a bed of particles is fluidized by two immisicible fluids. The principal application of TPFB with cocurrent upward flow of gas and liquid appears to be gas absorption, fermentation ${ }^{13}$ and catalytic hydrodesulfurization $^{9,10)}$. There are few useful equations for gasliquid mass transfer in TPFB.

For TPFB with cocurrent upward flow of gas and liquid, Østergaard and coworkers ${ }^{7,11}$ have reported as follows: the liquid-phase volumetric coefficient of mass transfer, $k_{i}^{*} a$, for $6-\mathrm{mm}$ glass spheres is about ten times larger than the coefficient for 1-mm spheres at low liquid-flow rates. In beds of 6 -mm particles, bubble break-up occurs and the gaseous phase forms a uniform dispersion of small bubbles at low liquidflow rates. Liquid mixing for beds of $6-\mathrm{mm}$ spheres may be neglected except at high gas-flow rates, whereas beds of 1-mm spheres are characterized by a high degree of mixing.

Muroyama et al. ${ }^{8}{ }^{\prime}$ have presented a map for hydrodynamic regions of coalesced bubble, dispersed bubble and slug flow. In beds of 3- to 5-mm spheres, dispersed bubble flow was observed at low gas flow rates.

For beds of $6-\mathrm{mm}$ glass spheres, $6.4 \mathrm{~cm}$ on the side in square section and $183 \mathrm{~cm}$ in height, Lee and Worthington ${ }^{6)}$ have reported data on gas holdup $\Phi_{g}$, interfacial area $a$ and $k_{l}^{*} a$ every $30 \mathrm{~cm}$ above the gas distributor.

For upward gas flow through stagnant liquid and 1.1-cm resin spheres, Kito et al. ${ }^{5)}$ have presented data for $\Phi_{g}$ and $a$ in $0.5 \mathrm{~N} \mathrm{NaOH}$ solution.

For packed columns with cocurrent upward flow (PCCU), an early report ${ }^{4}$ has presented the empirical equations for $a$ in terms of gas holdup per void fraction $\Phi_{g} / \varepsilon$, gas and liquid Reynolds numbers $R e_{g}$ and $R e_{l}$, and a ratio of packing to column diameter $d_{p} /$ $d_{T}$ for respective flow regions: bubble (I), churn, pseudospray, bubble (II), pseudopulse and pulse. It was also observed that the empirical equation of $k_{i}^{*}$ for packed columns with cocurrent downward flow

Received March 31, 1979.
(PCCD), in terms of $R e_{g}, R e_{l}$ and $d_{p} / d_{T}$ given in an earlier report ${ }^{3)}$ is applicable to illustrate the data for respective flow regions in PCCU.

The purpose of this investigation was to obtain the equations of mean bubble diameter, $d_{b}$, and $k_{l}^{*}$, for TPFB from the analysis of the literature data using the empirical equations of gas-liquid mass-transfer for $\mathrm{PCCD}^{3)}$ and $\mathrm{PCCU}^{4)}$ given in previous reports.

\section{Analysis of the Data and Discussion}

\section{Upward flow of gas and liquid}

1) Interfacial area and mean bubble diameter

The values of $\Phi_{g}$ and $a$ for beds of 6-mm glass spheres where $\varepsilon=0.72$ were measured by Lee and Worthington $^{6}$ ' using the $\gamma$-ray attenuation and light transmission methods, respectively. These values were observed at $17.6,47.6,77.6$ and $107.6 \mathrm{~cm}$ above a gas distributor with four nozzles. Figure 1 shows the dependence of $a d_{p} \varepsilon / \Phi_{g}$ on $R e_{g}$, where $R e_{l}=1106$. The thin solid line indicates the data rearranged by the least square method, except for the data at $107.6 \mathrm{~cm}$.

The empirical equation of $a$ for the bubble (I) flow region in PCCU is given in the early report ${ }^{4)}$ as follows:

$$
a d_{p} /\left(\Phi_{g} / \varepsilon\right)=16 \operatorname{Re}_{l}^{0.05} \operatorname{Re}_{g}^{-0.4}\left(d_{p} / d_{T}\right)^{0}
$$

The thick solid line representing Eq. (1) is only $10 \%$ lower than the thin solid line. This suggests that the liquid forms a continuous phase and that the gas was in uniform bubble distribution in an axial direction of TPFB, similar to the behavior of the bubble (I) flow region in PCCU.

The mean bubble diameter is given by

$$
d_{b}=6 \Phi_{g} / a
$$

Thus, Eq. (1) is rewritten as:

$$
d_{b} / d_{p}=0.38 \varepsilon R e_{l}^{-0.05} \operatorname{Re}_{g}^{0.4}\left(d_{p} / d_{T}\right)^{0}
$$

This equation supports the literature data ${ }^{7-10)}$ which indicate that small bubbles are obtained where $d_{p}$ is large, and the values of $\varepsilon$ and $R e_{g}$ are small.

According to the map of hydrodynamic flow region given by Muroyama et al. ${ }^{8\}}$, the Lee-Worthington data below $77.6 \mathrm{~cm}$ are located in the dispersed bubble flow region. However, as mentioned above, the flow pattern for dispersed bubble flow in TPFB shown by 


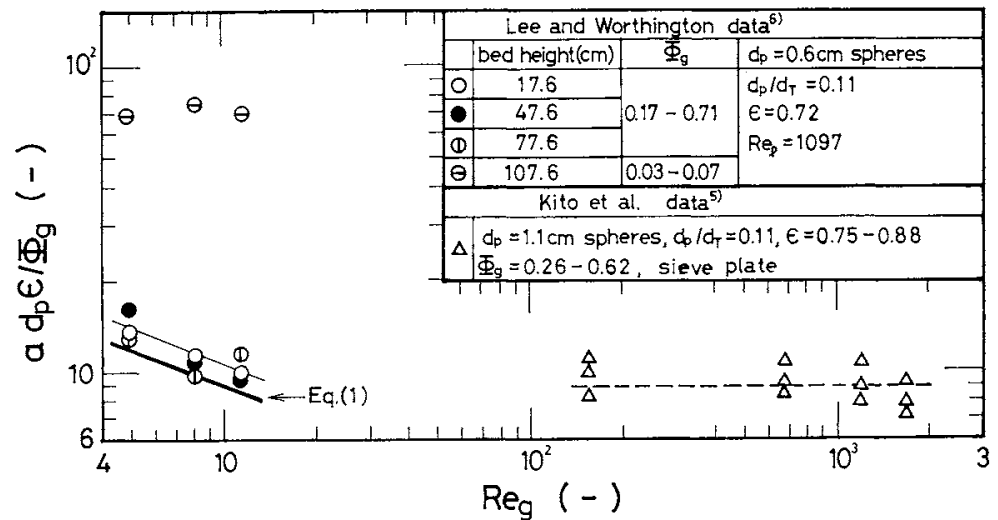

Fig. 1 Correlation of Eq. (1) and the Lee-Worthington data, and rearrangement of the Kito data

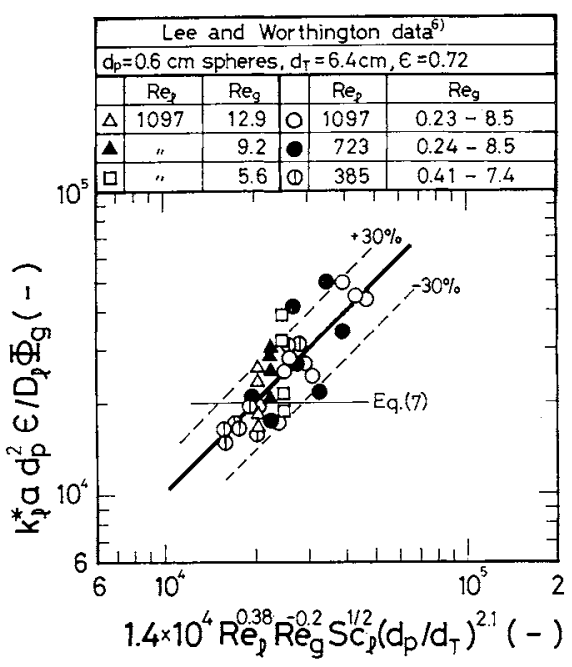

Fig. 2 Correlation of Eq. (6) and the Lee-Worthington data

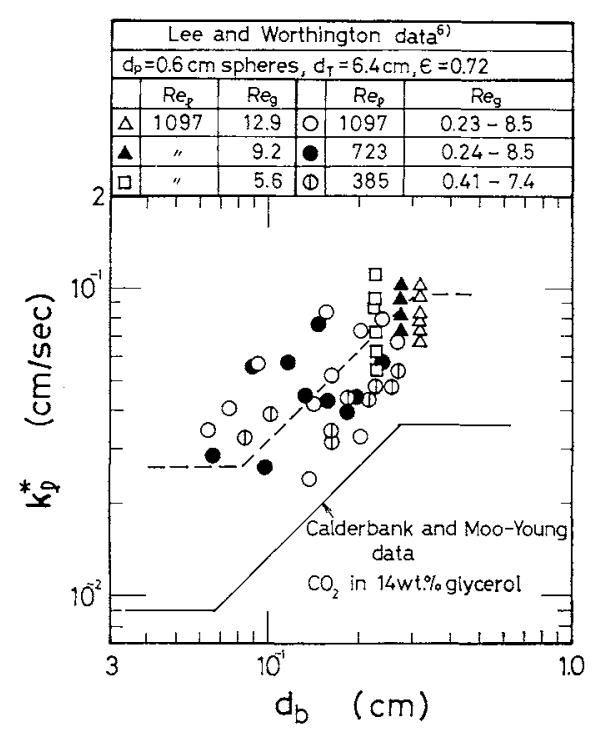

Fig. 3 Dependence of liquid-phase mass transfer coefficient on mean bubble diameter

Murayama et al. is similar to that for bubble flow (I) in PCCU.

In Fig. 1, the data for $107.6-\mathrm{cm}$ bed height are very different from the values predicted by Eq. (1). This supports the observation that the upper part of TPFB was a solid-free bed.

2) Liquid-phase mass-tranfer coefficient

The values ${ }^{6)}$ of $k_{l}^{*} a$ were obtained from the data on absorption rate of carbon dioxide into water every $30 \mathrm{~cm}$ above the gas distributor. The equation of $k_{l}^{*}$ for respective flow regions in PCCD and PCCU is simply given in the reports ${ }^{3,4}$ as follows:

$$
\begin{aligned}
S h_{l} & =k_{l}^{*} d_{p} / D_{l} \\
& =5 \times 10^{2} \phi^{0.3} \operatorname{Re}_{l}^{1 / 3} \operatorname{Re}_{g}^{1 / 5} \operatorname{SC}_{l}^{1 / 2}\left(d_{p} / d_{T}\right)^{2.2}
\end{aligned}
$$

Assuming that the exponent on $\left(d_{p} / d_{T}\right)$ in Eq. (4) is 2.1 instead of 2.2, the equation for TPFB of spheres is obtained as

$$
S h_{l}=8.9 \times 10^{2} \operatorname{Re}_{l}^{1 / 3} \operatorname{Re}_{g}^{0.2} S c_{l}^{1 / 2}\left(d_{p} / d_{T}\right)^{2.1}
$$

Hence, the equation for $k_{l}^{*} a$ is given by Eqs. (1) and (5) as follows:

$$
k_{l}^{*} a d_{p}^{2} \varepsilon / D_{l} \Phi_{g}=1.4 \times 10^{4} R e_{l}^{0.38} R e_{g}^{-0.2} S c_{l}^{1 / 2}\left(d_{p} / d_{T}\right)^{2.1}
$$

Lee and Worthington ${ }^{6)}$ have given the empirical equation for $k_{l}^{*} a$ as follows:

$$
k_{l}^{*} a / \Phi_{g}=1.53
$$

Figure 2 shows the correlation of Lee-Worthingtondata $^{8)}$ by Eq. (6). The thick solid line representing Eq. (6) agrees with the data within $\pm 30 \%$ error. But the thin solid line representing Eq. (7) leads to $250 \%$ error.

The dependence of $k_{l}^{*}$ on $d_{b}$ is also expressed by combining Eqs. (2) and (6) as follows:

$$
\left(k_{l}^{*} / d_{b}\right)\left(d_{p}^{2} \varepsilon / D_{l}\right)=2.3 \times 10^{3} R e_{l}^{0.38} R e_{g}^{-0.2} S c_{l}^{1 / 2}\left(d_{p} / d_{T}\right)^{2.1}
$$

For shallow-pool bubble-columns and bubble stirred tanks, Calderbank and Moo-Young ${ }^{2}$ have shown that large bubbles $\left(d_{b}>2.5 \mathrm{~mm}\right)$ give larger $k_{l}^{*}$ value than small bubbles $\left(d_{b}<2.5 \mathrm{~mm}\right)$. The $k_{l}^{*}$ value increases as $d_{b}$ increases in the transition region in which $d_{b}$ is about $2.5 \mathrm{~mm}$. The dependence of $k_{l}^{*}$ value on $d_{b}$ for TPFB is roughly in agreement with that observed in the transition region by Calderbank and Moo-Young ${ }^{2)}$, but the effect of $R e_{g}$ and $R e_{l}$ on $k_{l}^{*} / d_{b}$ cannot be neglected, as is seen from Eq. (8) or Fig. 3. 


\section{Upward flow of gas through stagnant liquid}

The free-expansion bed in which gas flows upward through stagnant liquid is capable of operating in a wide range of $R e_{g}$. For the gas $-0.5 \mathrm{~N} \mathrm{NaOH}$ solution system, the data on $\Phi_{g}$ and $a$ are given by Kito et $a l^{5)}$ for beds of $1.1-\mathrm{cm}$ resin particles, $10 \mathrm{~cm}$ in bed diameter, with a sieve plate used as gas distributor. The values of $a d_{p} \varepsilon / \Phi_{g}$ are independent of $R e_{g}$ and comparable to those in continuous liquid flow, as shown in Fig. 1. Thus, the gas-liquid behavior is analogous to that in the transition state between bubble (I) and pseudospray flow in PCCU.

\section{Conclusions}

Gas-liquid mass transfer characteristics for threephase fluidized beds of large spheres are obtained as follows.

1) The mean bubble diameter is predicted by an empirical equation of interfacial area for the bubble (I) flow region in packed columns with cocurrent upward flow.

2) The liquid-phase mass-transfer coefficient is also evaluated from a modification of the empirical equation for packed columns with cocurrent flow given previously.

\begin{tabular}{|c|c|c|}
\hline \multicolumn{3}{|c|}{ Nomenclature } \\
\hline$a$ & $\begin{array}{l}=\text { interfacial area per unit volume of } \\
\text { reactor }\end{array}$ & {$\left[\mathrm{cm}^{-1}\right]$} \\
\hline$D$ & $=$ diffusivity & {$\left[\mathrm{cm}^{2} / \mathrm{sec}\right]$} \\
\hline$d_{b}$ & $=$ mean bubble diameter & {$[\mathrm{cm}]$} \\
\hline$d_{p}$ & $=$ diameter of solid particles or packings & [cm] \\
\hline$d_{T}$ & $=$ diameter or side of reactor & {$[\mathrm{cm}]$} \\
\hline$k^{*}$ & $=$ mass transfer coefficient & {$[\mathrm{cm} / \mathrm{sec}]$} \\
\hline $\operatorname{Re}$ & $\begin{aligned}= & \text { Reynolds number for continuous medi } \\
& d_{p} u \rho / \mu\end{aligned}$ & Im, \\
\hline
\end{tabular}

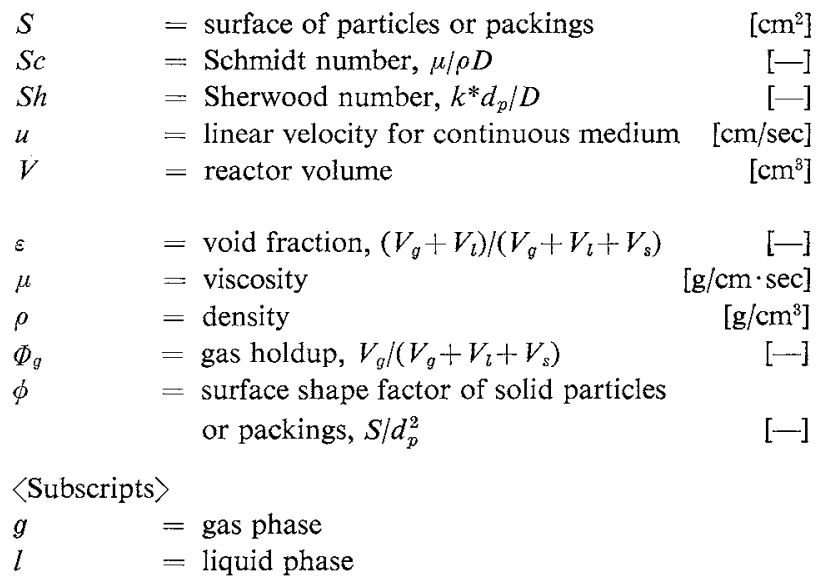

Literature

1) Atkinson, B. and I. J. Davies: Trans. Inst. Chem. Engrs., 50, 208 (1972).

2) Calderbank, P. H. and M. B. Moo-Young: Chem. Eng. Sci., 16, 39 (1962).

3) Fukushima, S. and K. Kusaka: J. Chem. Eng. Japan, 10, 468 (1977).

4) Fukushima, S. and K. Kusaka: ibid., 12, 296 (1979).

5) Kito, M., M. Shimada, R. Iijima, T. Sakai, M. Takata and S. Sugiyama: Kagaku Kogaku Ronbunshu, 2, 16 (1976).

6) Lee, J. C. and H. Worthington: Int. Chem. Eng., Symp. Ser., No. 38, "Multi-Phase Flow Systems", Vol. 1, B2 (1977).

7) Michelsen, M. L. and K. Østergaard: Chem. Eng. J., 1, 37 (1970).

8) Muroyama, K., K. Hashimoto, T. Kawabata and M. Shiota: Kagaku Kogaku Ronbunshu, 4, 622 (1978).

9) Østergaard, K.: "Advances in Chemical Engineering", Vol. 7, p. 71, Academic Press, New York, U. S. A. (1968).

10) idem: "Fluidization", edited by Davidson, J. F. and D. Harrison, p. 751, Academic Press, London, Great Britain (1971).

11) Østergaard, K. and F. Gosbøl: Chem. Eng. J., 3, 105 (1972). 